\title{
Bilateral olfactory dysfunction in early stage treated and untreated idiopathic Parkinson's disease
}

\author{
Richard L Doty, Matthew B Stern, Cheryl Pfeiffer, Steve M Gollomp, Howard I Hurtig
}

\begin{abstract}
Decreased olfactory function is among the first signs of idiopathic Parkinson's disease (PD). Whether such dysfunction is present to the same degree on both sides of the nose, however, is unknown. Furthermore, whether the deficit results from or is influenced by anti-Parkinsonian medications has not been definitely established. Odour identification ability was evaluated on the left and right sides of the nose in 20 early-stage untreated PD patients, 20 early-stage treated PD patients, and 20 controls. In all cases, the PD related olfactory dysfunction was bilateral and no difference was observed between the test scores of patients taking or not taking drugs for PD. Although asymmetries of unsystematic direction were present in the test scores of some PD patients, similar asymmetries were observed in the controls and the asymmetries were not related to the side of the major motor dysfunction. As in earlier work, no relation was present between the olfactory test scores and the degree of tremor, rigidity, bradykinesia, or gait disturbance at the time of testing. These findings indicate that the olfactory dysfunction of early stage $P D$ is robust, typically of the same general magnitude on both sides of the nose, and uninfluenced by anti-Parkinsonian medications.
\end{abstract}

School of Medicine, University of Pennsylvania, Philadelphia Smell and Taste Center and Department of Otorhinolaryngology

R L Doty

C Pfeiffer

Department of Physiology R L Doty

Department of Neurology and Graduate Hospital M B Stern

S M Gollomp

H I Hurtig

Correspondence to: Dr Doty, Director, Smell and Taste Center, 5 Ravdin Institute, Hospital of the Institute, Hospital of the 3400 Spruce Street, Philadelphia, PA 19104 (215662-6580)

Received 25 February 1991 and in revised form

8 July 1991

Accepted 17 July 1991

Decreased ability to smell is present in patients with early-stage Alzheimer's disease, ${ }^{1-5}$ idiopathic Parkinson's disease (PD), ${ }^{6-10}$ and the Parkinsonism-dementia complex of Guam (PDC). ${ }^{11}$ Although the physiological basis of these decrements is poorly understood, both peripheral and central segments of the olfactory pathways seem to be affected. For example, degenerative changes have been noted in the olfactory epithelium, the olfactory bulb, and the pyriform, prepyriform, and entorhinal cortices of patients with Alzheimer's disease. ${ }^{12-19}$ Although few studies of the neuropathology of the olfactory pathways of PD patients are available, near-total loss of cells within the anterior olfactory nucleus has been described for PDC. ${ }^{20}$

Recent studies suggest that the olfactory dysfunction of idiopathic PD does not progress significantly over time and is unrelated to the degree of motor and cognitive symptoms (implying independence from the more dynamic elements of the disease proper). ${ }^{67}$ Quantitative testing of only four untreated PD patients, however, has been reported in the literature ${ }^{10}$ and whether the olfactory loss is symmetric or asymmetric is unknown as only bilateral testing has been performed (such testing largely reflects the best functioning nasal chamber). ${ }^{21}$ Given that the olfactory projections have a very large ipsilateral component (possibly explaining why unilateral temporal lobe resection impairs odour identification ability in the nostril ipsilateral to the resected lobe), ${ }^{22}$ the presence of olfactory asymmetry might provide a marker for hemispheric differences in neurotransmitter function. Functional or anatomical asymmetries of dopaminergic systems have been suggested, on the basis of both neuropsychological and neurochemical findings, to be present in the central nervous system (CNS) of PD patients, although the differences are often subtle. ${ }^{2324}$

We studied whether the olfactory disorder of early-stage PD was asymmetric and, if so, whether the asymmetry was correlated with that observed in the motor system. We also compared the olfactory function of early-stage patients taking anti-Parkinsonian medications to that of early-stage patients not taking such medications.

\section{Materials and methods}

Subjects

patients with early PD who were enrolled in the DATATOP clinical trial. ${ }^{25}$ All of them had never taken or had stopped taking anti-Parkinsonian medications for a period of at least six weeks before olfactory testing. Five were left handed and the remainder right handed. Twenty patients with PD not enrolled in DATATOP who were taking anti-Parkinsonian medications at the time of the study made up the medicated study group, whereas 20 individuals without neurological disease served as normal controls. One of the medicated PD patients was left handed; all of the others and the control subjects were right handed. The three groups were selected to contain patients of similar age, sex, and smoking habits, since these factors are known to influence the olfactory measure used in this study. ${ }^{26-29}$ Within the group taking antiparkinsonian drugs, 19 were 
Table 1 Demographics of three study groups in parkinsonism study.

\begin{tabular}{lllc}
\hline & $\begin{array}{l}\text { Untreated patients } \\
(n=20)\end{array}$ & $\begin{array}{l}\text { Treated patients } \\
(n=20)\end{array}$ & $\begin{array}{l}\text { Normal } \\
\text { controls } \\
(n=20)\end{array}$ \\
\hline Mean (SD) age (years) & $61 \cdot 80(9 \cdot 76)$ & $62 \cdot 05(10 \cdot 14)$ & $65 \cdot 40(9 \cdot 66)$ \\
Mean (SD) length of education (years) & $15 \cdot 33(2 \cdot 63)$ & $13.90(2 \cdot 41)$ & $13.55(2 \cdot 42)$ \\
Male:female ratio & $15: 5$ & $15: 5$ & $15: 5$ \\
Number of current, previous, never & $1,9,10$ & 0.11 .9 & 3.10 .7 \\
cigarette smokers & $2 \cdot 63(0 \cdot 74)$ & $7 \cdot 43(3 \cdot 20)$ & - \\
Mean (SD) duration of symptoms (years) & $1 \cdot 47(0.47)$ & $1.55(0 \cdot 51)$ & - \\
\hline
\end{tabular}

taking Sinemet (1-dopa with carbidopa), either alone (eight patients) or in combination with anticholinergic drugs (such as benztropine) or other dopamine-related drugs (such as amantadin, bromocriptine) or both (11 patients). One patient was taking an anticholinergic drug alone (ethopropazine). The two groups of patients were statistically comparable in terms of age, gender, and smoking habits (table 1). The duration of the disease, however, was much shorter in the untreated than in the treated patients (group $\times$ gender analysis of covariance (ANCOVA) Group $F(1,35)=$ $30.93, \mathrm{p}<0.001$; covariate $=$ age). ${ }^{30}$ The mean age of the control group was higher than that of the untreated PD group $(t=3 \cdot 60, d f=$ $19, p=0.034$ ), largely because four controls could not be placed within a five year age bracket to their respective PD matches. These differences were of no consequence to the findings of the study, as there was no association between disease duration and the magnitude of the olfactory dysfunction (in concurrence with earlier work); ${ }^{6}$ the direction of the age difference would mitigate against the hypothesis of a PD related deficit in olfactory function ${ }^{27} 31$ (which, in fact, was found); and age was used as a covariate in most of the statistical analyses.

\section{Olfactory test procedure}

The University of Pennsylvania Smell Identification Test (UPSIT), ${ }^{26}$ a standardised forced choice test (commercially available as the Smell Identification Test ${ }^{\mathrm{TM}}$, Sensonics, Inc. Haddonfield, NJ) was chosen because of its ease of administration, strong correlations with more time consuming test measures (for example, olfactory thresholds), and high reliability. ${ }^{2632}$ The details of this test are presented elsewhere. ${ }^{26-293132}$ Briefly, each of the 40 pages of this four booklet test contain a microencapsulated ("scratch and sniff") odour and a related four alternative multiple choice question. The subject's task is to provide one of the four indicated answers, even if no smell is perceived (that is, the test is forced choice). The stimuli of this test span a wide range of qualitative odour classes, consist of both single and multiple component odorants, and are familiar and readily identifiable by most people within the context of a multiple-choice response format. ${ }^{26}$ Two booklets ( 20 odours) of the UPSIT were administered to each nasal chamber of the test subjects by a trained test administrator who released the stimuli under each subject's nose, read aloud the response alternatives, and recorded the responses. The nostril contralateral to the one being tested was comfortably but tightly sealed with a piece of Microfoam $^{\mathrm{TM}}$ tape (3M Corporation, Minneapolis, $\mathrm{MN}$ ) fitted to the perimeter of the naris. The tape insured that nasal inhalation occurred only on one side of the nose and precluded active retronasal movement of air to the receptors of the contralateral nasal chamber. ${ }^{33}$ The testing order of the nares and the presentation order of the UPSIT booklets was counterbalanced across subjects.

\section{Assessment of cognitive function}

All of the PD patients were given the 40 item Picture Identification Test (PIT), a forced choice visual test identical to the UPSIT except that line drawings, rather than odours, are used as stimulus items. ${ }^{34}$ This test is specifically designed to screen for patients whose aberrant UPSIT scores might be due to problems in comprehending non-olfactory components of the test rather than to problems in olfactory perception. The PIT correlates well with a number of neuropsychological measures and is sensitive to dementia-related cognitive deficits, as described elsewhere. ${ }^{7}$

\section{Assessment of neurological function}

Patients were staged according to the Hoehn and Yahr scale. ${ }^{35}$ The degree of tremor (left and right upper extremities), rigidity (left and right upper extremities), bradykinesia, and gait disturbance was rated on a standardised 4-point rating scale $(0=$ absent; $4=$ severe $)$ by neurologists with expertise in extrapyramidal disorders (MBS, HIH, SMG). With the exception of a single stage III patient, all patients were either stage I (25) or stage II (14).

\section{Results}

Relative to normal controls, both the treated and untreated PD patients showed decreased olfactory function on both sides of the nose (table 2). Because several PD patients had severe olfactory dysfunction, data are presented separately in table 2 for those patients whose total UPSIT score $(\mathrm{L}+\mathbf{R})$ was greater than 20 to establish whether systematic decreases in the test scores for one or the other side of the nose might be confined to cases with a better sense of smell. No significant left:right differences in the test scores were found (regardless of disease stage or level of olfactory functioning), and the test scores were unrelated to the side of PD-related motor disturbance and not significantly influenced by the use of anti-Parkinsonian drugs (all $p$ values $>0 \cdot 10$ ). No consistent relation was observed between the subjects' handedness and the asymmetry in the average test measures (for example, for right handed subjects the mean (SD) left and right UPSIT scores were $11.03(4.40)$ and 10.56 (4.18); analogous scores for left-handers $12.67(3.98)$ and $11.33(4.13)$ ), although the small number of left handed subjects (six) precluded a definitive statistical test of this issue. As expected, however, on the basis of previous studies ${ }^{67}$ the PD patients exhibited clear olfactory dysfunction not attributable to non-olfactory related cognitive problems (that 
Table 2 Mean (SD) University of Pennsylvania Smell Identification Test (UPSIT) scores for untreated and treated patients with Parkinsonism and normal controls. Dominant side is major body side of primary PD-related motor symptoms. Each nasal chamber was tested with 20 UPSIT items (total possible score 20)

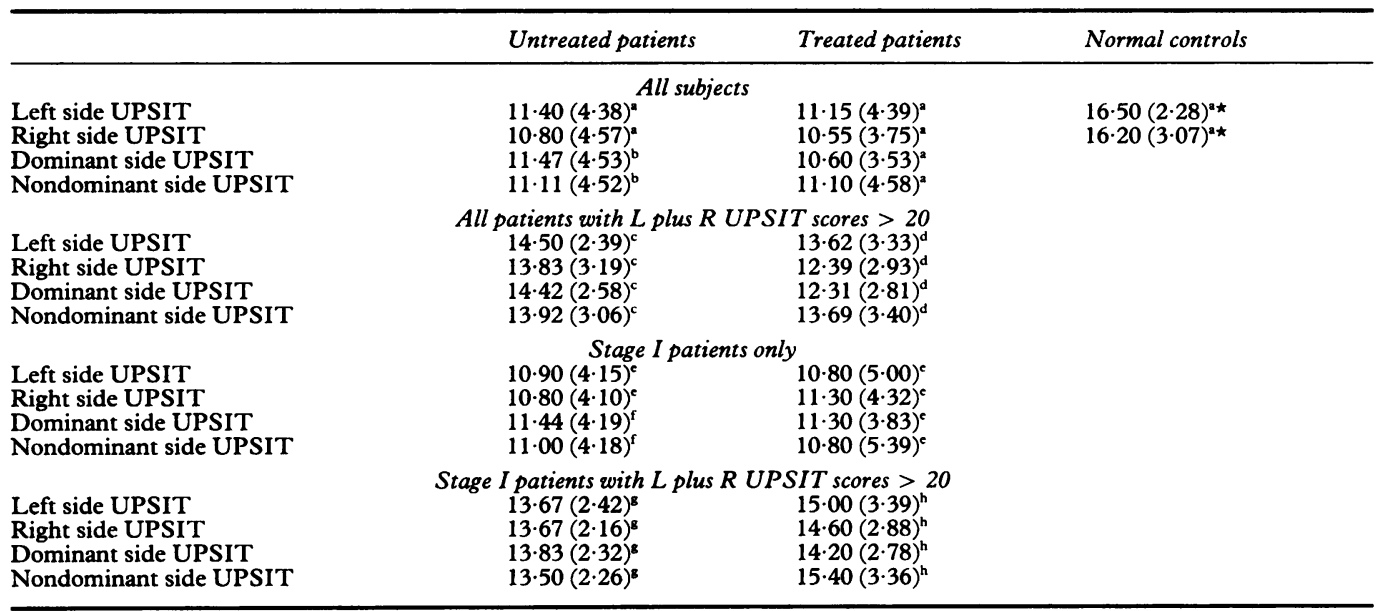

$\mathrm{n}=20 ;{ }^{\mathrm{b}} \mathrm{n}=19 ;{ }^{\mathrm{c}} \mathrm{n}=12 ;{ }^{\mathrm{d}} \mathrm{n}=13 ;{ }^{\mathrm{c}} \mathrm{n}=10{ }^{\mathrm{f}} \mathrm{n}=9 ;^{\mathrm{b}} \mathrm{n}=6{ }^{\mathrm{h}} \mathrm{h}=5$.

*Indicates controls differed significantly from each of the PD groups ( $p$ values $<0.001$; see text), which did not differ from one another. Analogous tests between untreated and treated groups were not significant in any subject category $(p$ values $>0 \cdot 10)$.

is, all but five scored $40 / 40$ on the PIT; the remainder missed three or fewer items). Thus, the left and right side UPSIT scores of the controls were significantly higher than the left and right side UPSIT scores of the two patient groups (group $\times$ gender ANCOVA; covariate $=$ age; group $\mathrm{Fs}(1,55)=7.69 \& 9.51$, p values $=0.008$ and 0.003 ), which in no case differed significantly from one another (post hoc comparison $p$ values $>0.20$ ). Women, on average, obtained higher UPSIT scores than men, regardless of the side of nose tested (left and right UPSIT gender Fs $(1,55)=5.55$ and 3.86 , $\mathrm{p}$ values $=0.022$ and $0.054 ;$ mean $(\mathrm{SD})$ left and right UPSIT scores for male and female PD patients and the male and female normal controls, respectively: 10.23 (4.03), $10.00(4.16)$, 13.78 (4.35), 13.22 (4.68), 16.33 (2.09), 15.73 $(3.28), \quad 17.00 \quad(3.00)$, and $17.60(1.95))$. Analogous ANCOVAs between the untreated and treated PD groups yielded no significant group $F$ values in any subject category ( $p>$ $0 \cdot 10$ ), although in most cases significant gender effects were observed ( $p$ values $<0.05$ ).

Most of the PD patients showed UPSIT scores on each side of the nose that were equivalent or relatively close to one another. Thus, $15 \%$ had equivalent scores on each side of the nose, $30 \%$ had scores differing by one UPSIT point, and $20 \%$ had scores differing by two UPSIT points. Scores differing by three, four, five and six UPSIT points were noted in the remaining $12.5 \%, 12.5 \%, 5 \%$, and $5 \%$ of the PD subjects, respectively. For the study group as a whole these differences were, on average, symmetrical (median (interquartile range) asymmetry value $=0(-1$ to $+2 \cdot 5)$, where negative numbers indicate larger right side values and positive numbers larger left side values). This average lack of asymmetry was also observed for the normal subjects where the median asymmetry value also was equal to 0 $(-3$ to $+2 \cdot 5)$. No meaningful associations were observed between the direction of the asymmetries in the PD patients and the side of the major PD symptoms, even in those subjects who evidenced the largest apparent olfactory asymmetries.

Few of the correlations computed among the variables (for example, gender, age, smoking status, Hoehn and Yahr stage, neurological ratings) for the $\mathrm{PD}$ groups combined were significant at $p=0.05$ (Bonferroni's correction for inflated alpha). ${ }^{36}$ Nevertheless, significant correlations were observed among the various olfactory measures (for example, left UPSIT $v$ right UPSIT $r=0 \cdot 81$; dominant side UPSIT $v$ nondominant side UPSIT $\mathrm{r}=0.80$ ) and among several neurological measures (for example, disease duration $v$ right rigidity $\mathbf{r}=$ 0.48 ; gait $v$ bradykinesia $=0.57$; left rigidity $v$ left tremor $r=0 \cdot 60$ ). The pattern of associations between the variables was similar to that observed in earlier studies, ${ }^{67}$ as shown by factor loadings extracted with a principal components factor analysis with a varimax rotation..$^{30}$ Because of this similarity, the details of the factor analysis are not presented here.

As in our earlier work, ${ }^{6}$ each patient was asked whether he or she suffered from any smell or taste problems before olfactory testing. Four men and one woman within the untreated group and two men and two women within the treated group indicated that they had such problems $(22.5 \%)$. Those aware of a smell problem before testing had lower UPSIT test scores than those who were unaware, also in accord with our earlier findings (respective means (SD): left side $8.44(3.25)$ v 11.84 (11.23); right side 9.00 (2.65) v 11.23 (4.36); left plus right sides $17.44(5.03) v 23.07(8.42)$; respective ANCOVA (covariates gender and age) group $F$ values $(1,35)=5.40(p=0.03)$, $4.36(\mathrm{p}=0.04), 5.51(\mathrm{p}=0.03))$.

\section{Discussion}

Our results show that the olfactory deficit observed in early PD is not secondary to the use of anti-Parkinsonian drugs and, for a given subject, is relatively similar on both sides of the nose. Although modest asymmetries were 
present in the test scores of some of the PD patients, no relation was observed between the direction or magnitude of such asymmetries and the side of the motor dysfunction of hemiParkinsonism. Importantly, the median olfactory asymmetry value of the PD patients was zero and the range of asymmetry values fell within that observed for normal subjects. As in the case of several other disorders in which olfaction is impaired, ${ }^{37}$ PD-related olfactory dysfunction was found to be less in women than in men. The basis of the olfactory dysfunction of PD is unknown, although it could reflect a PD-related vulnerability of the olfactory system to destruction by environmental factors or PD-related retrograde degenerative processes. Several theorists have proposed that some forms of Parkinsonism and other neurodegenerative disorders, such as Alzheimer's disease, may be caused by the entry of environmental agents or toxins from the nasal cavity into the brain. ${ }^{38}{ }^{39}$ The entry of viruses from the nasal cavity into the CNS is a well documented phenomenon, ${ }^{40-44}$ and several large macromolecules can readily enter the CNS of rodents and other animals from the nose ${ }^{45-48} \mathrm{PD}$ may be associated with a breakdown of the mucosal barrier which normally detoxifies xenobiotic agents and prevents them from damaging the olfactory membrane or from entering into the CNS via the olfactory receptors or surrounding mucosal tissue. ${ }^{49}$ Germane to this notion are observations that nasal tissues contain very high concentrations of enzymes that metabolise xenobiotics (for example, cytochromes P-450, flavin containing monooxygenase and aldehyde dehyrogenases, and carboxylesterases); $;^{50-52}$ metabolic rates for xenobiotics within nasal tissue typically exceed those of other extrahepatic tissues and commonly exceed those of the liver; ${ }^{53}$ and PD patients are less likely to detoxify drugs by sulphation or sulphoxidation than are similarly exposed controls. ${ }^{54}$

Whatever the basis for the olfactory dysfunction in PD, our patients showed average total UPSIT scores (L plus $R$ UPSIT values) which, for all practical purposes, were equivalent to the bilateral UPSIT scores of PD patients reported in earlier work (respective means (SD) $21.95(8.05) v 20.83(7.44)){ }^{6}$ This is in spite of the fact that all but one of the present subjects were at Hoehn and Yahr stage I or stage II of the disease process (compared to about half the subjects in the earlier study) and that nearly all had Parkinsonian symptoms for a much shorter period of time (respective symptom duration means in years (SD) $5.0(3.3) v$ $12.4(10 \cdot 1))$. While these similarities are most likely a reflection of similar degrees of olfactory pathology within the two groups and the independence of the UPSIT scores from disease stage and duration, two factors may have had some differential influence on the test scores. Firstly, our patients were nearly five years younger than those in the earlier study $(61.95 v 66.35$ years) and UPSIT scores are known to decline several points over this age period. ${ }^{27}{ }^{31}$ Secondly, bilateral UPSIT testing, on average, tends to result in slightly higher UPSIT scores than unilateral testing (for example, the L plus R UPSIT score obtained from unilateral administration in eight $P D$ subjects of the present study who had UPSIT scores $>18$ was significantly lower than the bilateral UPSIT score obtained from these same individuals; respective means (SD) 26.63 (9.15) $v 29 \cdot 13, t=3.50, p=0.024)$. Presumably these effects offset one another to about the same degree.

Supported by grant RO1 AG 08148 from the National Institute on Aging and grant PO1 DC 00161 from the National Institute on Deafness and Other Communication Disorders. We thank Kathy Shallow and the other members of the staff of the neurology department of Graduate Hospital for their assistance in data collection and Richard Frye and John Pierce for comments on an earlier version of the manuscript.

1 Doty RL, Reyes P, Gregor T. Presence of both odor identification and detection deficits in Alzheimer's disease. Brain Res Bull 1987;18:597-600.

2 Knupfer L, Spiegel R. Differences in olfactory test performance between normal aged, Alzheimer and vascular type mance between normal aged, Alzheimer and vascular type
dementia individuals. Internat J Geriatr Psychiat 1986; 1:3-14.

3 Warner MD, Peabody CA, Flattery JJ, et al. Olfactory deficits and Alzheimer's disease. Biol Psychiat 1986; 21:116-8.

4 Anasari KA, Johnson A. Olfactory function in patients with Parkinson's disease. J Chron Dis 1975;28:493-7.

5 Walden S. Clinical observations of impaired cranial nerve function in senile dementia. Acta Psychiat Scand 1974 50:539-47.

6 Doty RL, Deems DA, Stellar S. Olfactory dysfunction in parkinsonism: A general deficit unrelated to neurologic signs, disease stage, or disease duration. Neurology 1988; 38:1237-44.

7 Doty RL, Riklan M, Deems DA, Reynolds C, Stellar S. The olfactory and cognitive deficits of Parkinson's disease: evidence for independence. Ann Neurol 1989;25:166-71.

8 Serby M, Corwin J, Conrad P, Rotrosen J. Olfactory dysfunction in Alzheimer's disease and Parkinson's disdysfunction in Alzheimer's disease and
ease. Amer J Psychiat 1985;142:781-2.

9 Quinn NP, Rossor MN, Marsden CD. Olfactory threshold in Parkinson's disease. J Neurol Neurosurg Psychiatry 1987;50:88-9.

10 Ward CD, Hess WA, Calne DB. Olfactory impairment in Parkinson's disease. Neurology 1983;33:943-6.

11 Doty RL, Perl DP, Steele JC, et al. Odor identification defici of the parkinsonism-dementia complex of Guam: equivalence to that of Alzheimer's and idiopathic Parkinson's disease. Neurology 1991;41(suppl 2):77-80.

12 Averback P. Two new lesions in Alzheimer's disease. Lancet 1983;ii: 1204.

13 Esiri MM, Wilcock PK. The olfactory bulb in Alzheimer's disease. J Neurol Neurosurg Psychiatry 1984;47:56-60.

14 Hooper MW, Vogel FS. The limbic system in Alzheimer's disease. Amer J Pathol 1976;85:1-13.

$15 \mathrm{Ohm}$ TG, Braak H. Olfactory bulb changes in Alzheimer's disease. Acta Neuropathologaica 1987;73:365-9.

16 Pearson RCA, Esiri MM, Hiorns RW, Wilcock GK, Powell TPS. Anatomical correlates of the distribution of the pathological changes in the neocortex in Alzhemier disease. Proc Nat Acad Sci USA 1985;82:4531-4.

17 Reyes PF, Golden GT, Fagel PL, et al. The prepiriform cortex in dementia of the Alzheimer type. Arch Neurol 1987;50:113-5.

18 Talamo BR, Rudel R, Kosik KS, et al. Pathological changes in olfactory neurons in patients with Alzheimer's disease. Nature 1989;337:736-9.

19 Hirano A, Zimmerman HM. Alzheimer's neurofibrillary changes. A topographic study. Arch Neurol 1962;7: 227-42.

20 Perl DP, Levy D, Steele JC, Loerzel JA, Good PF, Doty RL. Severe neuronal loss in the anterior olfactory nucleus (AON) in parkinsonism-dementia complex (PDC) of (AON) in parkinsonism-dementia comp
Guam. Neurology 1990;40(suppl 1):405.

21 Koelega HS. Olfaction and sensory asymmetry. Chem Senses Flav 1979;4:89-95.

22 Eskenazi B, Cain WS, Novelly RA, Mattson R. Odor perception in temporal lobe epilepsy patients with and without temporal lobectomy. Neuropsychologia 1986; 24:553-62.

23 Bentin S, Silverberg R, Gordon HW. Asymmetrical cognitive deterioration in demented and Parkinson patients. Cortex 1981;17:533-44.

24 Direnfeld LK, Albert ML, Volicer L, Langlais PJ, Marquis J, Kaplan E. Parkinson's disease: the possible relationship of laterality to dementia and neurochemical findings. Arch Neurol 1984;41:935-41.

25 Parkinson Study Group. Effect of deprenyl on the progression of disability in early Parkinson's disease. New Engl $J$ Med 1989;321:1364-71.

26 Doty RL, Shaman P, Dann M. Development of the University of Pennsylvania Smell Identification Test: a standardized microencapsulated test of olfactory function. Physiol Behav (Monograph) 1984;32:489-502. 
27 Doty RL, Shaman P, Applebaum SL, Giberson R, Sikorsky $L$, Rosenberg L. Smell identification ability: changes with age. Science 1984;226:1441-3.

28 Doty RL, Applebaum SL, Zusho H, Settle RG. A crosscultural study of sex differences in odor identification ability. Neuropsychologia 1985;23:667-72.

29 Frye RE, Schwartz B, Doty RL. Dose-related effects of cigarette smoking on olfactory function. J Amer Med Assoc 1990;263:1233-6.

30 Wilkinson L. SYSTAT: the system for statistics. Evanson, IL: SYSTAT Inc, 1987.

31 Doty RL. The Smell Identification Test ${ }^{T M}$ administration manual. (2nd ed.) Haddonfield, Sensonics, 1989.

32 Doty RL, Ugrawal U, Frye RE. Evaluation of the internal consistency reliability of the fractionated and whole consistency reliability of the fractionated and whole
University of Pennsylvania Smell Identification Test University of Pennsylvania Smell Identificat

33 Burdach K, Doty RL. Retronasal flavor perception: influences of mouth movements, swallowing and spitting. Physiol Behav 1987:41:353-6.

34 Vollmecke T, Doty RL. Development of the Picture Identification Test (PIT): A research companion to the University of Pennsylvania smell identification test. Chem Senses 1985;10:413-4

35 Hoehn MM, Yahr MD. Parkinsonism: onset, progression, and mortality. Neurology 1967;17:427-42. 36 Myers JL. Fundamentals of experimental design (3rd ed.).

37 Deems DA, Doty RI, Settle RG, et al. Smell and taste disorders, A study of 750 patients from the University of Pennsylvania smell and taste center. Arch Otolaryngol Pennsylvania smell and taste center

38 Harrison PJ. Pathogenesis of Alzheimer's disease-beyond the cholinergic hypothesis: discussion paper. J Roy Soc the cholinergic hypo

39 Roberts R. Alzheimer's disease may begin in the nose and may be caused by aluminosilicates. Neurbiol Aging 1986; 7:561-7.

40 Barthold $S W$. Olfactory neural pathway in mouse hepatitis virus nasoencephalitis. Acta Neuropathol 1988;76:502-6.

41 Lundh B, Kristensson K, Norrby E. Selective infections of olfactory and respiratory epithelium by vesicular 1987;13:111-22.

42 Monath TP, Croop CB, Harrison AK. Mode of entry of a neurotropic arbovirus into the central nervous system: reinvestigation of an old controversy. Lab Invest 1983; 48:399-410.

43 Morales JA, Herzog S, Kompter C, Frese K, Rott R. Axonal transport of Borna disease virus along olfactory pathways in spontaneously and experimentally infected rats. Med Microbiol Immunol 1988;177:51-68.

44 Tomlinson AH, Esiri MM. Herpes simplex encephalitis immunohistological demonstration of spread of virus via olfactory pathways in mice. $J$ Neurol Sci 1983;60:473-84

45 Perl DP, Good PF. Uptake of aluminum into central nervous system along nasal-olfactory pathways. Lancet 1987; i: 1028 .

46 Shipley MT. Transport of molecules from nose to brain transneuronal anterograde and retrograde labeling in the rat olfactory system by wheat germ agglutin-horseradish peroxidase applied to the nasal epithelium. Brain Res Bull 1985;15:129-42.

47 Baker H, Spencer RF. Transneuronal transport of perox idase conjugated wheat germ agglutinin (WGA-HRP) from the olfactory epithelium to the brain of adult rat. Exp

48 Cancalon P, Beidler LM. Distribution along the axon and into various subcellular fractions of molecules labeled with ${ }^{3} \mathrm{H}$ leucine and rapidly transported in the garfish olfactory nerve. Brain Res 1975;89:225-44.

49 Doty RL. Olfactory dysfunction in neurodegenerative disorders. In: Getchell TV, Doty RL, Bartoshuk LM, Snow J $\mathrm{JB}$, eds. The chemical senses in health and disease. New York: Raven, 1991:735-51.

50 Dahl AR. Selective activation of carcinogens and other toxicants by nasal mucosae. In: Paton W, Mitchell $J$, Turnder P, eds. Proceedings of the Ninth IUPHAR Congress of Pharmacology, Vol 1. London: Macmillan, 1985:203-8.

51 Dahl AR. Activation of carcinogens and other xenobiotics by nasal cytochromes P-450. In: Boobis AR, Caldwell J, DeMatteis F, Elcombe CR, eds. Microsomes and drug oxidations. Philadelphia: Taylor and Francis, 1985: 299-309.

52 Dahl AR. Possible consequences of cytochrome P-450dependent mono-oxygenases in nasal tissues. In: Borrow CS, ed. Toxicology of the nose. Research Triangle Park NC: Chemical Industry Institute for Toxicology, 1985 263-71.

53 Dahl AR. The effect of cytochrome P-450-dependent metabolism and other enzyme activities on olfaction. In Margolis FL, Getchell TV, eds. Molecular neurobiology of the olfactory system. New York: Plenum Press, 1988: 51-70.

54 Steventon GB, Heafield MTC, Waring RH, Williams AC Xenobiotic metabolism in Parkinson's disease. Neurology 1989;39:883-7. 